\title{
Avaliação das aprendizagens no contexto de políticas curriculares de accountability ${ }^{1}$
}

\author{
José Augusto Pacheco \\ Universidade do Minho - Portugal \\ Ila Beatriz Maia \\ Universidade do Minho - Portugal
}

\section{Resumo}

$\mathrm{Na}$ discussão atual sobre processos de mudança e inovação, a nível curricular e pedagógico, há referências constantes a palavras-chave - por exemplo, qualidade, eficácia e eficiência - que definem não só práticas escolares, bem como políticas transnacionais e supranacionais de partilha de conhecimento, com efeitos no modo como a avaliação das aprendizagens é conceitualizada e realizada. Depois de uma discussão sobre políticas de accountability, que conduzem a práticas de performatividade nas escolas, ritual que é suportado cada vez mais pelos organismos transnacionais, por exemplo, através do conceito personalização da aprendizagem e da abordagem por competências globais, analisamos a avaliação das aprendizagens, nos ensinos básico e secundário, em Portugal, cujas práticas "deveriam ser" inovadoras em função do perfil de competências do aluno e das aprendizagens essenciais.

Palavras-chave: accountability; currículo; aprendizagem; agência; competência.

\section{Abstract}

In the ongoing discussion on change and innovation processes, at the curricular and pedagogical level, there are constant references to keywords - for example, quality, effectiveness and efficiency - that define not only school practices, but also transnational and supranational knowledge borrowing and lending policies, with effects on the way in which the assessment of learning is completed and carried out. After a discussion of policies of accountability, which lead to practices of performativity inside schools, a ritual that is increasingly supported by transnational organizations, for example through the concept of agency-learning and the approach by global competences, we analyze at the evaluation of learning in primary and secondary education in Portugal, whose practices "should be" innovative according

1 Este trabalho é financiado por fundos nacionais através da FCT - Fundação para a Ciência e a Tecnologia, I.P., no âmbito do projeto PTDC/CED-EDG/30410/2017 e dos projetos UID/ CED/1661/2013 e UID/CED/1661/2016 CIEd - Centro de Investigação em Educação, Instituto de Educação, Universidade do Minho. 
to the student's profile and essential core curriculum.

Keywords: accountability; curriculum; learning; agency; competence.

\section{Resumen}

En la discusión actual sobre procesos de cambio e innovación, a nivel curricular y pedagógico, hay referencias constantes a palabras clave - por ejemplo, calidad, eficacia y eficiencia - que definen no sólo prácticas escolares, así como políticas transnacionales y supranacionales de compartir conocimiento, con efectos en la forma en que la evaluación de los aprendizajes es conceptualizada y realizada. Después de una discusión sobre políticas de accountability, que conducen a prácticas de performatividad en las escuelas, ritual que es apoyado cada vez más por los organismos transnacionales, por ejemplo, a través del concepto de personalización del aprendizaje y del enfoque por competencias globales, analizamos la evaluación del aprendizaje en las escuelas primarias y secundarias en Portugal, cuyas prácticas "deberían ser" innovadoras en cuanto a lo perfil del estudiante y los aprendizajes esenciales.

Palabras-clave: accountability; currículo; aprendizaje; agencia; competencia.

\section{Résumé}

Dans la discussion en cours sur les processus de changement et d'innovation, aux niveaux curriculaire et pédagogique, il est constamment fait référence à des mots clés - par exemple, qualité, efficacité et efficience - qui définissent non seulement les pratiques scolaires, mais aussi les politiques transnationales et supranationales de partage des connaissances, avec des effets sur la manière dont l'évaluation des apprentissages est conceptualisée et réalisée. Après une discussion sur les politiques de responsabilisation, qui conduisent à des pratiques de performativité dans les écoles, un rituel de plus en plus soutenu par les organisations transnationales, par exemple à travers le concept de personnalisation de l'apprentissage et l'approche des compétences globales, nous analysons l'évaluation de l'apprentissage au Portugal, dans l'enseignement basic et secondaire, dont les pratiques "devraient être" innovantes en fonction du profil des compétences et des apprentissages essentiels de l'élève.

Mots-clés: responsabilité; curriculum; apprentissage; agence; compétence. 


\section{Introdução}

"Onde não há medição, existe a qualidade do todo" (Krishnamurti , 2019, p. 77).

Numa análise crítica das políticas educativas coevas, cujo berço são os organismos transnacionais e supranacionais (Charlot, 2013; Sellar \& Lingard, 2013), é comum dizer-se que a agenda escolar, na gestão do currículo, é normativa, técnica e burocrática e que, no processo de ensino e aprendizagem, é resultadista, performativa e produtivista.

Deste modo, e tendo por base quer os referenciais das políticas educativas formulado por Lessard e Carpentier (2016) - um, de modernização e democratização, outro, de produção eficaz e eficiente dos conhecimentos e competências exigidos pela sociedade e pela economia do conhecimento -, quer a noção dos comuns da escola (Labaree, 2012), os conceitos de qualidade, eficácia e eficiência impõem às escolas um método de comparação, presente nas políticas de partilha de conhecimento e nas políticas curriculares de accountability, responsáveis pelas suas práticas de performatividade.

Este ritual é liderado pelos organismos transnacionais, por exemplo, através do conceito de personalização da aprendizagem e da abordagem por competências (OCDE² 2018), mesmo que o enunciado das políticas de avaliação das aprendizagens, dos ensinos básico e secundário, em Portugal, remeta para práticas inovadoras em função do perfil de competências do aluno e das aprendizagens essenciais. No artigo são desenvolvidos quatro pontos: i) políticas de accountability, ii) escola dos comuns e resultados escolares, iii) avaliação das [para as] aprendizagens, iv) centralidade do aluno.

\section{Políticas de accountability}

Num estudo conceptual-empírico, Libâneo e Freitas (2018, p. 15) apresentam elementos para a "compreensão crítica do avanço das práticas políticas neoliberais internacionalizadas para dentro das escolas públicas, as quais diminuem drasticamente as possibilidades de democratização da escola pública no Brasil". Esta realidade não é única e aplicar-se-á, decerto, a muitos outros sistemas de educação e formação, sobretudo quando guiados por uma visão economicista que atinge o funcionamento interno das escolas em aspectos organizacionais, curriculares e pedagógicos. Assim, é comum dizer-se que, na procura de relações causais, os fatores que mais contribuem para essa realidade educativa dizem respeito à globalização e ao neoliberalismo, cujos pressupostos - qualidade, competição e escolha - impõem a lógica de mercado nas abordagens sobre o modo de organização e funcionamento da escola.

Desde a instituição da educação pública como interesse nacional e como obrigação 
do Estado (Charlot, 2013), e se for excluída até meados do século XX a ideia da escola para as elites, numa evidente hierarquização social, verifica-se que coexistem, hoje em dia, dois referenciais dominantes, como são formulados por Lessard e Carpentier (2016, p. 16):

"No conjunto do período estudado, identificamos dois referenciais: um de modernização e democratização, próprio dos Trinta Gloriosos ${ }^{3}$ (1945-1975), e um referencial da educação como produção eficaz e eficiente dos conhecimentos e competências exigidos pela sociedade e pela economia do conhecimento, que domina o período dos anos de 1990 até hoje".

Se bem que a democratização seja ainda uma palavra dominante em política educativa, a Escola para Todos é, ainda, um compromisso social, tal como preconizam os organismos transnacionais, por exemplo, Organização das Nações Unidas (ONU, 20154), Banco Mundial (BM, 2018), Fundo das Nações Unidas para a Infância (UNICEF, 2017) e Organização para a Cooperação e Desenvolvimento Económico (OCDE, 2018), mesmo que a lógica da eficácia/eficiência conduza a uma abordagem de mercado para a educação, e consequentemente expressa como teoria curricular (Pacheco, 2018a).

Muita argumentação invocada consiste precisamente em dizer que os sistemas educativos "não conseguiram produzir cidadãos capazes de contribuir para esse novo mundo" (Lessard \& Carpentier, p. 37), criado pela globalização e pela sociedade baseada na economia do conhecimento, fazendo depender o desempenho dos alunos de fatores socioeconómicos e da sua mensuração através da definição não só de conteúdos nacionais (core curriculum), mas também de standards ou padrões de desempenho. No entanto, "o antigo referencial não desapareceu da memória das instituições e dos agentes e o novo referencial não reina incontestavelmente" (Ibid., p. 48).

O referencial de mercado traduz uma linguagem de accountability que se materializa contínua e persistentemente nas escolas, quer pela valorização dos resultados e standards, o que equivale a governamentalidades curriculares que estreitam o currículo e definem um perfil de gestor para a ação do professor, quer pela mensuração como estratégia de inovação, como se verifica pelas agendas do Banco Mundial (2018), que insiste na avaliação da aprendizagem como objetivo prioritário, pois se está quase cumprido o objetivo da escola para todas as crianças e jovens ainda falta cumprir o da aprendizagem essencial para todos eles, e da OCDE (2014), em que a inovação, intrinsecamente ligada à mensuração, através de indicadores comparativos internacionais, é assumida como estratégia de melhoria, nomeadamente nos estilos de ensino, nas práticas pedagógicas, na organização de turmas, no uso de textos e

$3 \quad$ Período de prosperidade económica.

4 De acordo com os Objetivos de Desenvolvimento Sus $\neg$ tentável, da ONU, formulados em 2015, é imperativo "assegurar a educação inclusiva, equitativa e de qualidade, e promover oportunidades de aprendizagem ao longo da vida para todos" ( $4^{\circ}$ objetivo) 
manuais na sala de aula, nos métodos de avaliação utilizados na sala de aula, no uso de computadores e da Internet na sala de aula, nos apoios de educação especial na escola, na colaboração dos professores na escola, na avaliação das escolas e na relação da escola com a comunidade.

\section{Escola dos comuns e resultados escolares}

Numa síntese realizada nos últimos duzentos anos sobre as mudanças na escola dos Estados Unidos da América, e com o objetivo de analisar os seus opostos, ou seja, de um lado, a igualdade e, do outro, a desigualdade, Labaree (2012) fala dos reformadores sociais crônicos, ou seja, os que pretendem confiar à escola a missão da resolução de problemas sociais, num compromisso de garantir o acesso de todos os alunos à escola, mesmo que permaneça a síndrome da escola, assim enunciada: a crença, quase sempre adiada, de que a escolaridade pode, de qualquer modo, melhorar a sociedade, promover o acesso e preservar as suas vantagens.

Num tempo de dois séculos, o autor identifica dois grupos principais: os reformadores e os consumidores. Os reformadores têm operado três mudanças essenciais: i) movimento da escola comum através da criação de uma escolaridade básica universal e financiada publicamente, com livre acesso, controle local e escassos standards acadêmicos. Assim, a escola tem sido pública, ainda que dominada por uma linguagem de controle e prescrição (Tyack \& Cuban, 1995), originando o que Grinnel e Rabin (2013) chamam tragédia dos comuns, fazendo da escola um lugar por excelência de procedimentos uniformes.

Trata-se da criação de uma escola comum, marcada, grosso modo, pelas questões organizacionais, ou seja, pela forma de organizar a escolaridade, que foi sucessivamente melhorada e tornada universal. Esta retórica organizacional tem sido ineficaz porque traduz a "inabilidade de os reformadores entrarem na sala de aula", bem como a secundarização do modo "como os professores ensinam e os alunos aprendem" (Labaree, 2012, p. 144). Com efeito, privilegia-se a inovação em linha com o sistema, apesar do impacto limitado que as mudanças têm provocado nas escolas, mesmo que a escola pública seja um desígnio da democracia liberal, com o propósito de formar o cidadão para uma nova ordem social, tornando a escola num rationale político; ii) movimento progressista da escola, ou da educação nova ${ }^{5}$, com poucas orientações em comum, mas contendo uma diversidade de elementos individuais, como é preconizado, entre outros, por Dewey (1902/2002), que distingue a escola tradicional da escola dos interesses dos alunos; iii) movimento dos standards curriculares (ou dos parâmetros curriculares ou dos padrões de desempenho), através do estabelecimento de planos a nível nacional, de orientações curriculares comuns,

5 Para Newton Duarte, Os conteúdos escolares e a ressurreição dos mortos, 2016, p. 82 “o projeto educativo da escola nova não conseguiu colocar no lugar da escola tradicional algo que tivesse a mesma força educativa". 
de testes em larga escala e de melhoria dos resultados escolares. Este movimento tem sido cíclico, tendo começado, na década de 1950, com a pedagogia por objetivos, prosseguido, na década de 1960, com a pedagogia por competências, e desde a década de 1980, com os programas de standards implementados nos Estados Unidos (A Nation at Risk, No Left Child Behind, Race to Top), reforçados pela linguagem das competências globais (OCDE, 2018).

$\mathrm{Na}$ análise crítica destes três movimentos de reforma, Labaree (2012) conclui que os resultados de mudança têm tido pouco impacto na melhoria da escola, mantendo os seus princípios organizacionais ligados ao sistema e criando diretrizes para a organização do currículo a nível institucional, mantendo os resultados como fim último da escola e da aprendizagem, originando nos professores o terror da performatividade (Ball, 2003).

Pelo contrário, os consumidores - aqueles que através das suas ações perseguem os seus interesses individuais através da escolaridade - apontam para um impacto na escola menos modesto que os reformadores, na medida em que consideram que a educação é um bem privado, e não um bem público, e que o seu objetivo não é o de "tentar mudar as escolas ou reformar a sociedade" (Labaree, 2012, p. 149), pressionar o governo para o uso dos recursos financeiros na educação pública. Além disso, as mudanças, propostas pelos consumidores, para alterar as práticas de aprendizagem têm pouco impacto, estando mais preocupados com a forma da escolaridade do que com o seu conteúdo, ou seja, os consumidores não são reformadores da escola, apenas tentam "estar à frente ou pelo menos não ficar para trás" (Ibid., p. 149), sendo mais decisivo que a escola seja uma moeda curricular para a empregabilidade, aceitando como válido na escola os diplomas, os níveis de escolaridade e a hierarquia das aprendizagens ligada aos testes. Assim, os consumidores acreditam convictamente no progresso da educação através da sociedade, "fé esta que é alimentada pelas classes médias urbanas, para as quais um diploma escolar foi e ainda é o capital necessário à mobilidade social ou, mais prosaicamente, um meio de impedir uma possível desclassificação" (Lessard \& Carpentier, 2016, p. 15).

Face a estes de grupos de reforma, Labaree (2012) conclui: se a escola é uma criação do movimento da escola comum, realizada pelos reformadores, a sua força motriz tem sido da responsabilidade dos consumidores, cuja lógica de mercado tem diversas vozes e várias direções, pelo que não é movimento único e muitas das suas ações são partilhadas pelos diferentes grupos sociais, operando interactivamente as dinâmicas de mercado.

Ainda nas palavras de Labaree (2012), "os consumidores não só inundaram o sistema com alunos, como também transformaram a estrutura do sistema. Tornaram a escola comum, onde todos têm a mesma experiência, numa escola incomum, onde todos entram na mesma instituição, mas seguindo diferentes programas" (Ibid., p. 150), tal como se verifica na escola do ensino secundário ou na escola do ensino básico, quando os alunos são confrontados com diferentes percursos de escolarização. 
Rapidamente, o sistema se foi adaptando aos consumidores e a orientação política tem correspondido à ideologia liberal presa a ideias de um mercado educacional, cujo valor a escola começa a construir pela diversificação de percursos, pelas barreiras, de natureza social, econômica e cultural, que são colocadas numa corrida de obstáculos, onde todos os alunos parecem ter, à partida, as mesmas oportunidades de ganhar.

Por isso, os consumidores têm sido ora mais eficazes nas mudanças, mantendo quer a racionalidade política, que não contestam, desde que o mercado seja a prioridade do Estado, quer a estrutura do sistema educativo, mediante exigências de resultados acadêmicos, ora mais ineficazes na promoção da desigualdade social, associando a mobilidade social a hierarquias de grupos que a escola ajuda a construir, como tem sido analisado por muitos autores, a exemplo de Lipovetsky (2012). Neste caso, como reconhece Labaree (2012, p. 153), o sistema escolar não tem sido bem-sucedido na sua missão social. Depois do sucesso inicial, o movimento da escola pública, "pouco fez para promover as metas comuns, a igualdade democrática e a mobilidade social. Não tem sido capaz de promover a igualdade de raça, classe e género". Numa frase, já dita por Tyack e Cuban (1995), a escola tem regras que alteram as reformas, já que ela tem uma gramática de natureza organizacional, curricular e pedagógica.

A este propósito, será curável a síndrome do sistema escolar? Na resposta, Labaree (2012, p. 155) diz que não, porque não acredita no remédio que tem sido utilizado, havendo algo de intrigante, pois "permite que as escolas mudem continuamente e que preservem muito mais do mesmo", sendo eficientes naquilo que fazem e não naquilo que seria suposta não fazerem, pelo que o sistema, passados dois séculos, continua a ser disfuncional.

Numa escola dos comuns (organizacional, curricular e pedagógico), a racionalidade de Estado agrafa ao ensino e à aprendizagem figuras es-tereotipadas do professor e do aluno, como se a sociedade fosse única e imutável no modo como organiza curricularmente a escola, na base da pedagogia prescritiva de Comênio (1657/1985) e de Ratke (1635/2008), da pedagogia racional de Kant (1803/2017), da pedagogia científica de Herbart (1806/2010), da teoria de instrução de Bruner (1915-2016) e do racional de Tyler (1902-1994).

A escola de resultados, traduzidos em standards de conteúdos, capacidades, atitudes e valores, tão presente nos testes nacionais e internacionais (caso do PISA), torna-se numa alquimia do conhecimento (Popkewitz, 2011), cuja validade orientada pelas necessidades do mercado equivale à procura de uma pedra filosofal, de modo a resolver os problemas da sociedade. Contudo, é uma escola que exclui e não inclui, partindo-se do princípio que a estratificação social é a base da competição e que a diversificação dos percursos escolares, segundo uma teoria curricular bifurcada entre as mãos e o cérebro (Goodson, 2001), é um modo efici_entista de promover não só a excelência escolar, em que os melhores são cada vez melhores e os fracos são cada vez mais fracos, mas também a competição entre professores, alunos e pais, unidos pelo receio em falhar (Taubman, 2009). 
Neste caso, a escola constrói a qualidade através de processos de avaliação reportados a referenciais externos, nomeadamente a avaliação institucional, com incidência no domínio dos resultados escolares, a avaliação do desempenho docente, no quadro de fatores marcadamente burocráticos e desligados da sala de aula, e a avaliação das aprendizagens que é moldada pelos testes internos e externos e pelo método comparativo.

Este método valoriza o desempenho mensurável dos alunos, sobretudo nos exames, advertindo Krishnamurti (2019, p.9) que "atribuímos demasiado peso aos exames e a conseguir altos graus académicos" e que "o ponto mais alto da medição são os exames, que são acompanhados pelo medo e pela ansiedade, os quais irão afetar negativamente a vida futura do aluno. Toda a atmosfera da escola muda por completo quando nela não existe o sentido da competição ou da comparação" (Ibid., p. 111).

Por isso, os resultados que pretensamente expressam a qualidade da aprendizagem, no reforço de uma proposição que dita regras de mensuração, estudadas psicológica e docimologicamente (Bruner, 1966/1999), é entendida num ciclo pedagógico sumativo em que os conteúdos são essencialmente adquiridos na base da memorização, ou seja, "a maior parte da nossa educação consiste na aquisição de conhecimentos, tornando-nos mais e mais mecânicos; as nossas mentes funcionam ao longo de caminhos estreitos, quer o conhecimento adquirido seja científico, filosófico, religioso, econômico ou tecnológico" (Krishnamurti (2019, p.11). E mais: “a autoridade da comparação destrói. Quando um estudante é comparado com outro, ambos são atingidos. Viver sem comparação é ser-se íntegro. Estarão os educadores dispostos a desempenhar tal tarefa?" (Ibid., p. 51).

Os testes em larga escala, com incidência nos testes transnacionais, de que o PISA é o padrão, o ranking de escolas e a linguagem das competências, uma outra forma de apresentar objetivos de aprendizagem, originam não só uma escolarização restrita, como também a coerção avaliativa, em que a avaliação é marcada pelos resultados entendidos como scores numa prática de competição. Deste modo, a escola centrada em resultados confronta o professor com o que pode ser denominado recontextualização performativa, isto é, uma coerção avaliativa, tanto ao nível da produção de discursos, como no plano das práticas, que sobrepõe as questões técnicas às pedagógicas, nomeadamente, questões sobre "a eficiência e eficácia do processo educacional" (Biesta, 2013, p. 41).

No estudo realizado sobre os efeitos da performatividade no sistema público, Ball (2014) diz que tais políticas tratam de um modo de governação liberal, requerendo profissionais que respondam a uma avaliação estandardizada e que não resistam à paixão da excelência, pois isso representa terem sucesso perante os outros, apesar da opacidade pedagógica que provoca através da fabricação de mecanismos de produção da excelência, razão porque afirma que a educação (e também a formação de professores, acrescentamos) está transformada "num grande negócio" (Ball, 2012, p. 116). 
Com efeito, a escola assume-se como espaço privilegiado de criação de normas comuns, nas perspetivas organizacional, curricular e pedagógica, carregadas de burocracia que tenta chegar aos pormenores do modo de fazer, limitando o tempo para desenvolvimento profissional docente, exaltando os testes e a publicitação de resultados obtidos em provas de avaliação externas e aceitando a regulação no quadro de políticas de partilha de conhecimento (Steiner-Khamsi, 2012; Ball, 2014), cuja lógica neoliberal impõe uma ordem regida "pela eficácia, pela meritocracia, pela utilidade e pela produtividade" (Lipovetsky, 2013, p. 126).

\section{Avaliação da [e para a] aprendizagem}

Em países mais centralizados, como Portugal, e tendo como ponto de partida o plano curricular, com a designação de disciplinas e tempos letivos, bem como o programa, um dispositivo de identificação dos conteúdos a serem aprendidos em cada ano de escolaridade, a organização tradicional do currículo nacional sofre um revés. Agora fala-se em competência (conhecimentos, capacidades, atitudes e valores) e a sua fundamentação está ligada a um movimento de reforma global, no sentido de reafirmação da lógica da escola dos comuns (organizacional, curricular e pedagógico). Entretanto, os testes em larga escala, principalmente o PISA, contribuem de modo significativo para esse comum, cuja validade social é avaliada quase exclusivamente pelos resultados comparativos a nível internacional. E assim estão criadas as condições para a definição do currículo do século XXI à imagem e semelhança da OCDE, cuja preponderância nos sistemas educativos se torna crescentemente efetiva nas últimas décadas (Sellar \& Lingard, 2013), mais ainda com o relatório The future of Education and Skills, Education, 2030, cuja leitura é norteada por estas duas questões essenciais: Que conhecimentos, capacidades, atitudes e valores os alunos de hoje precisam para prosperar e partilhar o seu mundo? De que modo os sistemas educativos podem desenvolver, de forma eficaz, tais conhecimentos, capacidades, atitudes e valores? (OCDE, 2018).

Tais questões baseiam-se num currículo que será flexível e dinâmico, já que escolas e professores devem ser capazes de atualizar e alinhar o currículo, tendo em atenção os requisitos sociais e as necessidades individuais de aprendizagem. Também é dito que o currículo deve estar bem alinhado com as práticas de ensino e avaliação, surgindo desse modo uma prática de alinhamento curricular. Desse modo, o core curriculum é constituído por planos curriculares nacionais, perfil de alunos à saída da escolaridade obrigatória e aprendizagens essenciais. Se a primeira peça do currículo nacional é flexivelmente colocada, mas apenas a $25 \%$ mais no seu processo que no 
seu conteúdo, a segunda peça traduz dez competências transversais ${ }^{6}$ e vários perfis profissionais (ensino profissional) e a terceira torna-se num denominador comum das aprendizagens.

Com efeito, as aprendizagens essenciais, referenciadas por ciclo e ano de escolaridade ${ }^{7}$, são o denominador comum da avaliação externa e, consequentemente, do que é ensinado nas escolas e salas de aula, reforçando a ideia de que, hoje em dia, a escola pela sua missão de inclusão e equidade social tem de garantir a progressão dos alunos com qualidade das aprendizagens e também num sentido de valorização da aprendizagem significativa (Ausubel, 1963, 2003), da avaliação formativa (Scriven, 1967; Stake, 2006), da pedagogia diferenciada (Meirieu, 1998; Dewey, 1902/2002) e da pedagogia por descoberta (Bruner, 1973), pressupostos de uma avaliação para $a$ aprendizagem (Alves, 2004).

Se os conteúdos das disciplinas têm uma tradição na escola, a perspetiva de ir mais além dos conteúdos valoriza uma noção de educação mais ampla, que não fica restrita ao que deve ser aprendido e que dá sentido à subjetivação do currículo, ou seja, consideração do aluno, e também do docente, como sujeito, cuja aprendizagem envolve a sua esfera privada e a sua esfera social em termos de mente, corpo e sensibilidade. No sentido de criar uma escola educativa e uma nova cultura de aprendizagem, no quadro de uma nova racionalidade, Pérez Gómez (2012, p. 99) salienta que

"a finalidade da escola não se esgota no ensino e na aprendizagem dos conteúdos disciplinares estabelecidos no currículo e organizados nos livros de texto [manuais]. A missão da escola é a de ajudar ao desenvolvimento das capacidades, competências e qualidades humanas fundamentais que são requeridas para que o cidadão contemporâneo possa viver de modo satisfatório nos complexos contextos da era da informação: Que qualidades humanas, capacidades e competências são estas? Quem as define? Como são desenvolvidas?".

\section{Centralidade do aluno}

Se a escola já esteve - ou ainda estará, mesmo se o professor for substituído pelo manual ou por um dispositivo digital? - centralizada no professor e no seu magister

$6 \quad$ Reconhece-se a existência de diferentes tipos de competências que necessariamente estão associados a formas concretas de saber : competência cognitiva, relacionada com a ciência do conhecimento (Rey, 1996), de natureza académica (Barnett, 1997; Perinat, 2004); competência operacional (Barnett, 1997; Perinat, 2004), de natureza comportamental e funcional (Rey, 1996); competência metodológica, de natureza complexa (Rey, 2005, et al) e interdisciplinar (Rey, 1996; Allal, 2004). Cf. José A. Pacheco, Discursos e lugares das competências em educação e formação, 2011; José A. Pacheco, Educação, formação e conhecimento, 2014.

7 Cf. Despacho n. 6944-A/2018, de 19 de julho e Despacho n. 8476-A/2018, de 31 de agosto, de homologação das Aprendizagens Essenciais do Ensino Básico e do Ensino secundário, respetivamente. 
dixit, as organizações internacionais colocam o aluno no centro das aprendizagens. Porém, em tempos em que a aprendizagem é avaliada por indicadores que contribuem para a aquisição de competências globais (OCDE, 2018), os resultados são recolocados no centro da escola. Como resolver esta aparente contradição?

Relendo textos transnacionais, como o da OCDE (2013, p. 2) sobre avaliação, observa-se que as políticas educativas definem uma avaliação baseada em indicadores de desempenho, dentro de um movimento mundial assim caracterizado: "crescente procura de eficiência, equidade e qualidade na educação", "tendência na educação em direção a uma maior autonomia escolar, que tem acarretado o aumento da necessidade de avaliar o desempenho escolar", "aperfeiçoamentos nas tecnologias da informação, que possibilitam o desenvolvimento da avaliação dos alunos em grande escala e a nível individual, e facilitam a divulgação e gestão de dados" e "maior dependência nos resultados de avaliações com vista à tomada de decisões com base em evidência"

Ainda neste relatório, a avaliação implicará os seguintes desafios:

"Adotar uma abordagem holística; alinhar a avaliação com os objetivos do ensino; enfatizar a melhoria das práticas em sala de aula; evitar as distorções no processo de ensino; colocar os alunos no centro do quadro de avaliação; desenvolver competências a todos os níveis; gerir as necessidades locais; conceber com êxito e construir consensos" (Ibid., pp. 2-4).

Em resposta a tais desafios, a OCDE (2018), partindo de uma abordagem por competências globais (conhecimentos, capacidade, atitudes e valores) pretende elaborar um quadro conceitual de aprendizagem baseado em evidências, ou seja, numa lógica eficientista que confere lugar de destaque à inovação pedagógica através de políticas baseadas em resultados ou, mais concretamente, de accountability, mesmo que o referencial da democratização não seja abandonado discursivamente. Mas o predomínio dos testes é largamente reconhecido como instrumento privilegiado de accountability escolar (Carnoy, Elmore, \& Siskin, 2003). Para Koretz (2017, p. 8), o lado positivo caminha a par do lado negativo:

"Não questiono os motivos porque muitas pessoas pressionaram para que fosse adotada nas escolas uma accountability baseada em testes. Muitas, eu sei de fato, tinham as melhores intenções: elas queriam melhorar a qualidade das escolas, ajudar todos os alunos a aprender mais e a reduzir as lacunas entre os alunos favorecidos e desfavorecidos. Contudo, nem as intenções nem o valor dos testes bem utilizados justificam que se continue a ignorar os absurdos e os fracassos do sistema atual, bem como os danos reais que estão a causar".

Neste caso, o olhar dos organismos internacionais (BM9, 2017; UNICEF, 2017; OCDE, 2016) está essencialmente direcionado não para os melhores alunos, cujos resultados são apresentados numa forte correlação com o fator socioeconômico,

8 Documento citado "Sinergias para uma melhor aprendizagem: uma perspetiva internacional sobre avaliação. Sumário em Português”.

$9 \quad$ Nas referências, World Bank. 
mas para os alunos com piores resultados, sobretudo daqueles que não conseguem terminar a escolaridade obrigatória ou que, cumprindo-a, não adquirem o domínio de saberes fundamentais. Aliás, pela força dos discursos de excelência escolar, há uma generalizada valorização social das escolas cujos alunos têm os melhores resultados, reinando o silêncio relativamente aos alunos que estão no limiar da escola. Face a esta realidade, e porque no currículo não se pode evitar esta questão, Westbury, em entrevista a Rug (2018, p. 12) reforça "que temos esse enorme problema dos resultados", reconhecendo para os testes internacionais: "um desfecho lamentável da avaliação internacional à larga escala é que as pessoas no primeiro quartil das escolas ficam loucas por melhorar a realização dos seus alunos e as do quartil inferior das escolas não se importam nem um pouco" (Ibid., p.8).

Um dos pilares desse quadro pedagógico será a agência do aluno, isto é, a personalização do aluno no processo de aprendizagem, pois o currículo deve ser construído em torno dos alunos para os motivar e reconhecer seus conhecimentos, suas habilidades, suas atitudes e seus valores prévios (OCDE, 2018). Por conseguinte, em termos de inovação, e dentro dos seus diferentes significados (Fullan, 2015), a atual agenda da OCDE é orientada por um processo rigoroso de mensuração, com a elaboração e aplicação de testes em larga escala que só por si permitam não apenas a criação e o uso de uma linguagem comum para países, autoridades locais, escolas, professores, estudantes e outros agentes interessados, mas também a existência de uma comunicação eficaz, baseada na colaboração e na evidência de dados, de modo que seja possível aprender e comparar as melhores práticas.

Como a OCDE não resolve esta contradição de preconizar ao mesmo tempo aprendizagens orientadas para os números e para as pessoas (Pacheco, 2018b), será pertinente repensar a escola nas suas finalidades. Um dos possíveis elementos de resposta consistirá em perguntar para que servem as escolas. Young (2007) afirma que as escolas existem para realizar as ideias de democracia e justiça social, bem como a ideia de promover a aquisição do conhecimento, pensamento partilhado por Nóvoa (2017, p. 1120):

"Para mim, a escola tem dois pilares centrais: o conhecimento e a mobilidade social. O conhecimento é indissociável de lógicas pessoais e colegiais, de um conhecimento que reside também na experiência e nas "comunidades profissionais" que o produzem e difundem. A mobilidade social tem, sobretudo, uma dimensão pessoal, mas prolonga-se por expectativas que abrangem os grupos e as comunidades em que cada um está inserido".

Outra resposta consiste na rejeição de uma aprendizagem apressada em detrimento de uma aprendizagem ampla e profunda, já que "as águas profundas são mais calmas. Raramente a aprendizagem profunda é rápida ou apressada" (Hargreaves e Fink, 2007, p. 63), sendo que o conhecer lento, "que lança as sementes da criatividade e do engenho, é cada vez mais negligenciado nas escolas" (Ibid., p. 63), pelo que "não vale a pena melhorar os resultados nos testes, se eles não refletirem uma aprendizagem ampla e profunda" (Ibid., p. 303), bem como de um ensino para os testes, que origina a aprendizagem apressada e faz com que as escolas também sejam apressadas. Assim, 
"o currículo é abarrotado com mais conteúdos, fazem-se mais testes, os conceitos são transmitidos a grupos de idade mais novos, dedica-se mais tempo aos aspetos básicos que serão testados, os professores dão menos tempo aos alunos para responderem a questões nas aulas e as perguntas e a curiosidade começam a evaporar-se" (Ibid., p. 68).

Por último, a resposta das tecnologias digitais. O admirável mundo da inovação que se reconhece a nível científico através do uso de tecnologias digitais, com impacto em todos os setores da sociedade, também tem incidência no sistema educativo, em geral, e nas práticas curriculares, em particular?

Se, no campo da tecnologia, a inovação está ligada a ideias que fazem a diferença, no sentido da busca de um novo que é original, em educação os seus significados são perspectivados de outro modo, sempre com a presença de algo que é novo, mesmo que não seja original, porque tal ideia ou tal prática já foi anteriormente apresentada e realizada. Com efeito, os professores estão comprometidos com três mudanças substantivas: com o futuro, mas não obliterando o passado e as presentes circunstâncias que tornam o percurso escolar difícil para muitos alunos; com uma aprendizagem real dos alunos, e não meramente com a obtenção de resultados em testes estandardizados, aprendizagem essa que não é apressada, mas profunda, na integração de saberes-chave que são convocados para a sua realização - colaboração, criatividade, pensamento crítico, cidadania, carácter e comunicação (Fullan \& Mceachen, 2018); com uma aprendizagem personalizada, associada às tecnologias digitais, não deixando de ser críticos quanto a estas tecnologias estarem a contribuir para um saber apressado, disponível, mas não refletido.

Por outro lado, as tecnologias digitais têm forte impacto no modo de aprender, com mudanças exponenciais proporcionadas pela inteligência artificial, que permitirá uma aprendizagem amplificada a níveis inimagináveis, naquilo que é designado por superinteligência recursiva (Leonhard, 2017) e que resultará da fusão pessoa-máquina, cuja capacidade cognitiva poderá exceder o mais admirável dos intelectos humanos em toda a história (Ibid., p. 39), por exemplo, através de implantação de "dispositivos de estimulação cognitiva no cérebro para aumentar o nosso desempenho" (Ibid., p. 59).

Não restam dúvidas de que as tecnologias digitais estão a mudar modos de ensinar e aprender, com alterações radicais no domínio de competências cognitivas e na construção de redes de conhecimento, contribuindo para a personalização da aprendizagem, tão propalada por empresas globais como a Google. Assim, "as tecnologias digitais criaram a possibilidade de tornar onipresente a comunicação de quase todos os tipos de conteúdos (livros, vídeos, jornais, música) e desmaterializar muitos dos serviços" (Vieira, 2019, p. 34) e com a internet "o mundo tornou-se um local completamente ligado, com milhões de dispositivos que comunicam entre si, em qualquer local e em qualquer altura" (Ibid., p. 34). 
No entanto, a suposta individualidade tem uma existência intrinsecamente coletiva, no contexto de uma obesidade digita ${ }^{10}$, realçando mais a rede, a sabedoria das massas, a colaboração e a uniformização do que a identidade e diversidade. Aliás, como ainda refere Leonhard (2017, p. 215), o peso das tecnologias digitais no quotidiano das pessoas, e sobretudo quando tecnologia é sinónimo de inovação e eficiência, obriga a colocar estas duas interrogações: a) "Será que a ideia de eficiência total se vai tornar o grande ponto de equilíbrio, forçando-nos a um comportamento mais uniforme?"; b) "Será que a obsessão com a tecnologia e a sua absoluta eficiência e consistência acabarão por anular a aceitação tácita da diferença e da ineficiência humana?”.

De forma também preocupante, Bartlett (2018) denuncia como a tecnologia e a democracia, enquanto dois grandes sistemas, contraditórios na sua caracterização e funcionamento, tendem para situações de controle desregulado pelo mercado, colocando em causa modos de viver em sociedade tidos como fundamentais para a liberdade do sujeito. Se "o desenvolvimento de sistemas inteligentes, sejam eles programas ou robôs, tem enorme potencial para o progresso da humanidade" (Vieira, 2019, p. 91), o tempo atual é de grande desafio, os tempos atuais representam um desafio mais significativo para a escola, que terá de rever profundamente o seu modo de ensinar e aprender, mas não para a educação, uma vez que a singularidade tecnológica ${ }^{11}$ - ou de máquinas que adquirem não só inteligência e a desenvolvem de modo recursivo, mas também são portadoras de consciência - não pode representar a negação do desenvolvimento integral da pessoa humana e da sua emancipação.

E este é um desafio que é colocado mais uma vez à escola, não sendo possível desimaginá-lo e negá-lo, mesmo que a linguagem da instrução esteja a sobrepor-se à linguagem da educação (Biesta, 2013). Normativamente, em Portugal, exige-se ao professor "dinâmicas pedagógicas" que incluam, além de outras características,

"o trabalho de natureza interdisciplinar e de articulação interdisciplinar e de articulação disciplinar, operacionalizado preferencialmente por equipas educativas que acompanham turmas ou grupo de alunos; a atuação preventiva que permita antecipar e prevenir o insucesso e o abandono escolares; a implementação das medidas multinível, universais, seletivas e adicionais que se revelem ajustadas à aprendizagem e inclusão dos alunos; a rentabilização eficiente dos recursos e oportunidades existentes na escola e na comunidade; a adequação, diversidade e complementaridade de estratégias de ensino e aprendizagem, bem como a produção de informação descritiva sobre os desempenhos dos alunos; a regularidade da monitorização, avaliando a intencionalidade e o impacto dasestratégias e

10 Para Gerd Leonhard, Tecnologia versus humanidade. O confronto futuro entre a máquina e o homem, 2017, p. 151, a obesidade digital é "uma doença mental e tecnológica em que dados, informações, meios de comunicação social e conetividade digital são acumulados até ao ponto de terem um efeito sobre a saúde e bem-estar, a felicidade e a vida em geral".

11 Para Arlindo Vieira, Inteligência artificial, 2019, pp. 96-97, "O desenvolvimento de um sistema superinteligente ou a criação de uma tecnologia que permita emular integralmente um cérebro humano num computador teriam, caso ocorressem, consequências dramáticas no funcionamento da sociedade ... O termo singularidade foi ... inventado por John von Neumann, em 1957.... A designação vem da Matemática, área em que uma singularidade representa um ponto onde uma função matemática se torna "singular" e descontínua". 
Tais dinâmicas pedagógicas permitiriam "reforçar as dinâmicas de avaliação das aprendizagens centrando-as na diversidade de instrumentos que permitem um maior conhecimento da eficácia do trabalho realizado e um acompanhamento ao primeiro sinal de dificuldade nas aprendizagens dos alunos", numa "complementaridade entre os processos de avaliação interna ${ }^{13}$ e externa das aprendizagens ${ }^{14 "}$. Partese do pressuposto de que a avaliação é "sustentada por uma dimensão formativa", considerando os "conhecimentos adquiridos, bem como as capacidades e atitudes desenvolvidas no âmbito das áreas de competências inscritas no perfil dos alunos à saída da escolaridade obrigatória" e nas "aprendizagens essenciais" ${ }^{15}$, duas peçaschave do currículo nacional, cuja construção nas escolas é recontextualizada (Leite, Fernandes \& Figueiredo, 2018).

\section{Conclusão}

Mais do que uma conclusão que traduza as ideias ut supra, preferimos lançar algumas interrogações, na argumentação de duas ideias principais: a primeira é que a medição da aprendizagem não traduz a qualidade, pois "a palavra mais é sempre comparativa, assim como a palavra melhor" (Krishnamurti, 2019, p. 110), perguntando-se: "poderá o educador pôr de lado toda a comparação, toda a medição no seu trabalho educativo? Será ele capaz de aceitar o aluno tal como ele é, não como deveria ser, e não emitir juízos baseados em apreciações comparativas? (Ibid., p.111).

A segunda para diferenciar instrução de educação, num processo de formação ampla e integral do aluno, já que as políticas educativas subordinadas a uma linguagem de accountability determinam a escola dos resultados e dos seus números comparados e não a escola das pessoas, que existe para que alunos aprendam a conhecer, a viver num mundo que não pode esgotar-se no conhecimento. Neste sentido, Dewey (1902/2002, p. 161) escreve que "possuir todo o conhecimento do mundo e perder a própria pessoa é um terrível destino da educação".

A realidade de hoje das escolas é complexa. Os alunos são outros, os professores são outros e as escolas parece que em nada mudaram, como se os comuns fossem algo de trágico que contraria a inovação. Olhar para dentro da escola curricularmente

12 Cf. Decreto-lei n. 55/2018, de 6 de julho.

13 Os critérios de avaliação são definidos por cada escola.

14 No ensino básico, para além de provas aferidas, que não contam para a progressão dos alunos, há provas nacionais no $9^{\circ}$ ano de escolaridade e exames nacionais no ensino secundário, nos $11^{\circ}$ e $12^{\circ}$ anos, conforme a disciplina seja terminal ou não. Tanto na avaliação interna como na avaliação externa, o ensino básico tem uma escala numérica de 1 a 5 , com exceção do $1^{\circ}$ ciclo (do $1^{\circ}$ ao $4^{\circ}$ ano de escolaridade, em que a avaliação é descritiva) e o ensino secundário uma escala numérica de 0 a 20.

15 Cf. Decreto-lei n. 55/2018, de 6 de julho. 
inteligente (Leite, 2003) é um enorme desafio, tornando-se urgente discutir respostas pertinentes para estas questões:

- Que conhecimento é mais valioso? (Spencer, 1859).

- Quem decide o conhecimento que é avaliado? (Lingard, 2018).

- Que conhecimento é mais apropriado para ser avaliado? (Ibid.)

- Os alunos aprenderam o que os outros exigiram? (Jung \& Pinar (2016).

$\mathrm{Na}$ análise crítica de possíveis respostas, sempre incompletas, será possível discutir, por um lado, que referenciais têm definido as políticas educativas, que racionalidades têm justificado a construção de projetos curriculares e que linguagens têm influenciado a formação dos alunos como pessoas e como aprendentes de um dado conhecimento. Todavia, outras respostas são inultrapassáveis, por exemplo, as que dizem respeito à formação de professores (Leite \& Fernandes, 2010), ao papel da escola em tempos marcados pela aprendizagem ao longo da vida e à função da avaliação, nas suas diferentes dimensões (organizacional, curricular e pedagógica) e nas suas facetas integradas (avaliação institucional, avaliação do desempenho docente e avaliação das [e para] as aprendizagens).

\section{Referências}

Alves, M. P. (2004). Currículo e avaliação. Porto: Porto Editora.

Ausubel, D. P. (1963). The psychology of meaningful verbal learning. New York: Grune \& Stratton.

Ausubel, D. P. (2003). Aquisição e retenção de conhecimentos: uma perspectiva cognitiva. Lisboa: Plátano.

Ball, S. J. (2003) The teacher's soul and the terrors of performativity. Journal of Education Policy, 18 (2), 215-228, doi: 10.1080/0268093022000043065

Ball, S. J. (2012). Global education inc. New policy networks and the neo-liberal imaginary. London: Routlege.

Ball, S. J. (2014). Educação global S. A. Novas redes politicas e o imaginário neoliberal. Ponta Grossa: Editora UEPG.

Bartlett, J. (2018). The people Vs Tech. How the internet is killing democracy (and how we save it). London: Ebury Press.

Biesta, G. (2013). Para além da aprendizagem. Educação democrática para um futu- 
ro humano. Belo Horizonte: Autêntica.

Bruner, J. (1966/1999). Para uma teoria da educação. Lisboa: Relógio D’Água.

Bruner, J. (1973). La pédagogie pour découverte. Paris: Payot.

Bruner, J. S. (1966/1999). Para uma teoria da educação. Lisboa: Relógio D’Água.

Carnoy, M., Elmore, R., \& Siskin, L. S. (Eds.). (2003). The new accountability. High schools and high-stakes testing. London: Routledge Falmer.

Charlot, B. (2013). Da relação com o saber às práticas educativas. São Paulo: Cortez Editora.

Dewey J. (1902/2002). A escola e a sociedade. A criança e o currículo. Lisboa: Relógio D’Água.

Duarte, N. (2016). Os conteúdos escolares e a ressurreição dos mortos. São Paulo: Autores Associados.

Fullan, M. (2015). The new meaning of Educational change (5th ed.). New York: Teachers College Press.

Fullan, Q., \& Mceachen, J. (2018). Deep learning. Engage the world change the world. Thousand Oaks, California: Corwin.

Grinnel, S., \& Rabin, C. (2013). Modern education: a tragedy of the commons. Journal of Curriculum Studies, 45 (76), 748-767.

Hargreaves, A., \& Fink, D. (2007). Liderança sustentável. Porto: Porto Editora.

Jung, J., \& Pinar, W. F. (2016). Conceptions of curriculum. In D. Wyse, L. Hayward \& J. Pandya (Eds.), The Sage Handbook of Curriculum, Pedagogy and Assessment (pp. 29-46). London: Sage.

Koretz, D. (2017). The testing charade. Pretending to make schools better. Chicago: The University of Chicago Press.

Krishnamurti, J. (2019). Carta às escolas. Lisboa: Edições 1970.

Labaree, D. F. (2012). School syndrome: understanding the USA's magical belief that schooling can somehow improve society, promote access, and preserve advantage. Journal of Curriculum Studies, 44 (2), 143-163. doi:10.1080/00220272.2012.675 358 
Leite, C. (2003). Para uma escola curricularmente inteligente. Porto: Edições Asa.

Leite, C., \& Fernandes, P. (2010). Educação, 33 (3),198-204.

Leite, C., Fernandes, P., \& Figueiredo, C. (2018). Challenges of curricular contextua lization: teachers' perspectives. The Australian Educational Researcher, 45 (4), 435 453. doi:10.1007/s13384-018-0271-1

Leonhard, G. (2017). Tecnologia versus humanidade. O confronto futuro entre a máquina e o homem. Lisboa: Gradiva.

Lessard, C., \& Carpentier, A. (2016). Políticas educativas. A aplicação na prática. Petrópolis: Editora Vozes.

Libâneo, J. C. (2013). Internacionalização das políticas educacionais e repercussões no funcionamento curricular e pedagógico das escolas. In J. C. Libâneo, M. V. Suanno \& S. V. Limonta (Org.), Qualidade da escola pública. Políticas educacionais, didática e formação de professores (pp. 13-46). Goiânia: CEPED.

Lingard, B. (2018). Reforming education: the spaces and places of education policy and learning. In E. Hultqvist, S. Lindblad \& T. Popkewitz (Ed.), Critical analyses of edu cational reforms in an era of transnational governance. Amsterdam: Springer.

Lipovetsky, G. (2012). A sociedade da deceção. Lisboa: Edições 70, 2012.

Lipovetsky, G. (2013). A era do vazio Ensaios sobre o individualismo contemporâneo.

Meirieu, P. (1998). Pedagogia entre o dizer e o fazer. Porto Alegre: artmed.

Nóvoa, A. (2017). Firmar a posição como professor, afirmar a profissão docente. Cadernos de Pesquisa, 47 (166), 1106-1133.

OECD (2013). Synergies for better learning: an international perspective on evaluation and assessment. Paris: OECD Publishing. doi:10.1787/9789264190658-en

OECD (2014). Measuring innovation in education. A new perspective. Paris: OECD.

OECD (2016). Low-performing students: why they fall behind and how to help them suceed,PISA. Paris: OECD Publishing http://dx.doi.org/10.1787/9789264250246-en.

OECD (2017). Measuring innovation in education: a journey to the future. Paris: OECD.

OECD (2018). The future of education and skills, Education, 2030.Paris: OECD.

Oliveira, A. (2019). Inteligência artificial. Lisboa: Fundação Francisco Manuel dos 
Santos.

ONU (2015). Guia sobre o desenvolvimento sustentável. Centro de Informação Regional das Nações Unidas para a Europa Ocidental, disponível em: www.unric.org/pt, acesso a 27 fev. 2019.apara transformar o nosso mundo

Pacheco, J. A. (2014) Educação, formação e conhecimento. Porto: Porto Editora.

Pacheco, J. A. (2018b). Saberes e aprendizagens. Entre os números as pessoas. Contrapontos, 18 (1), 45-54. doi: http://dx.doi.org/10.14210/contrapontos.v18n1.p4554

Pacheco, J.A. (2011). Discursos e lugares das competências em educação e formação. Porto: Porto Editora.

Pacheco, J.A. (2018a). Para uma teoria curricular de mercado. In J. A. Pacheco, M. C. Roldão \& M. T. Estrela (Org.), Estudos de currículo (pp. 57-88). Porto: Porto Editora.

Pérez Gómez, A. (2012). Educarse en la era digital. Madrid: Morata.

Popkewitz, T. (2011). PISA: Numbers, standardizing conduct, and the alchemy of Scholl subjects. In M. A. Pereyra, H. Kotthoff \& R. Cowen (Eds.). PISA under examination. Changing knowledge, changing tests, and changing schools (pp. 31-46). Rotterdam: Sense Publishers.

Ruzgar, M. E. (2018). On matters that matter in the curriculum Studies: an interview with Ian Westbury. Journal of Curriculum Studies. doi:

10.1080/00220272.2018.1537374

Scriven, M. (1967). The methodology of evaluation. In R. Stake (Ed.), AERA monogra phy series on curriculum evaluation. Chicago: Rand Macnally.

Sellar, S., \& Lingard, B. (2013). The OECD and global governance in education. Journal of Education Policy, 28 (5) :5, 710-725.doi: 10.1080/02680939.2013.779791 Spencer, H. (1859). What knowledge is Most Worth? Westminster Review.

Stake, Robert (2006). Evaluación compreensiva y evaluación basada em estándares. Barcelona: Graó.

teiner-Khamsi, G. (2012). Understanding policy borrowing and lending. Building com parative policy studies. In G. Steiner-Kkamsi \& F. Waldow (Eds.), World yearbook of education 2012. Policy borrowing and lending in education (pp. 5-17). London: Routledge.

Taubman, P. (2009). Teaching by numbers. Deconstructing the discourse of standards and accountability in education New York: Routledge. 
Tyack, D., \& Cuban, L. (1995). Tinkering toward utopia. A century of public school re form. Cambridge: Harvard University Press.

UNICEF (2017). For Every Child (2017). Disponível em: https://www.unicef.org/publi cations/index_95950.html, acesso a 30 dez. 2017.

World Bank (2018). Learning to realize education's promise, 2018. Disponivel em: http://www.worldbank.org/en/publication/wdr2018, acesso a 2 out. 2018.

Young, M. F. (2007). Para que servem as escolas? Educação \& Sociedade, 28, (101), 1287-1302.

\section{Biografia}

\section{José Augusto Pacheco}

Professor Catedrático do Instituto de Educação da Universidade do Minho. (Estudos Curricular e Tecnologia Educativa)

Email: jpacheco@ie.uminho.pt ORCID: https://orcid.org/0000-0003-4623-6898

\section{Ila Beatriz Maia}

Estudante de pós-graduação do Instituto de Educação da Universidade do Minho. Universidade do Minho

Email: ib.maia@hotmail.com 